\title{
Forecasting Wheat Crop Statistics with the Use of Space Technology and Ground Based Information of Uttarakhand State
}

\author{
Divya Uniyal ${ }^{1}$, V.K.Dhuandiyal ${ }^{1}$ \\ ${ }^{1}$ Uttarakhand Space Application Centre (USAC), Dehradun, Uttarakhand
}

\begin{abstract}
Wheat is an economically important Rabi crop for the state, which is grown on around $26 \%$ of total available agriculture area in the state. There is a variation in productivity of wheat crop in hilly and tarai region. The agricultural productivity is less in hilly region in comparison of tarai region due to terrace cultivation, traditional system of agriculture, small land holdings, variation in physiography, top soil erosion, lack of proper irrigation system etc.

Pre-harvest acreage/yield/production estimation of major crops is being done with the help of conventional crop cutting method, which is biased, inaccurate and time consuming. Remote Sensing data with multi-temporal and multi-spectral capabilities has shown new dimension in crop discrimination analysis and acreage/yield/production estimation in recent years.

In view of this, Uttarakhand Space Applications Centre (USAC), Dehradun with the collaboration of Space Applications Centre (SAC), ISRO, Ahmedabad and Uttarakhand State Agriculture Department, have developed different techniques for the discrimination of crops and estimation of pre-harvest wheat acreage/yield/production. IRS (Indian Remote Sensing Satellites), LISS-III, LISS-IV satellite data of Rabi season for the year 2013-14 along with ground data were used for acreage/production estimation. Results were compared with Bureau of Estimation Statistics (BES). For yield estimation, a relationship has been found out between MNDVI values and Yield collected from ground. To get the production estimation, estimated yield multiplied by acreage of crop per hectare. Result shows deviation for acreage estimation from BES is around $1.6 \%$ estimation and deviation for production estimation is around $2.9 \%$, The estimated data has been provided to State Agriculture department for their use. To forecast production before harvest facilitate the formulation of workable marketing strategies leading to better export/import of crop in the state, which will help to lead better economic condition of the state. Yield estimation would help agriculture department in assessment of productivity of land for specific crop. Pre-harvest wheat acreage/production estimation, is useful to facilitate the reliable and timely estimates and enable the administrators and planners to take strategic decisions on import-export policy matters and trade negotiations.
\end{abstract}

Key Words: Acreage, Production, LISS-III, NDVI, Geo-referencing, Hierarchical Decision rules Security classification: Unrestricted

\section{Introduction}

Wheat is an economically important Rabi crop for the Uttarakhand state, which is grown on around $26 \%$ of total available agriculture area in the state. There is a variation in productivity of wheat crop in hilly and tarai region. The agricultural productivity is less in hilly region as comparison of tarai region due to terrace cultivation, traditional system of agriculture, small land holdings, variation in physiography, top soil erosion, lack of proper irrigation system etc.

A timely forecast of any crop helps the government in farming policies regarding its storage, distribution, export-import and procurement of price. Various methods ranging from conventional to Remote Sensing methods are used for crop production forecasting. Crop production forecasts consist of two components acreage and yield which are forecast separately. In this study an attempt has been made to estimate acreage of wheat crop for Uttarakhand state using LISS-III data.

Estimates for wheat crop is provided by Agriculture statistics department, Government of India a project for making production forecasts for wheat crop was taken by Department of Space(DOS) as project FASAL (Forecasting Agricultural Output using Space, Agrometorological and Land based observations) USAC with the collaboration of SAC (Ahmedabad). IRS LISS-III data of January and February was used for acreage estimation. MXL classifier was used to discriminate wheat from other crops.

In this study an attempt has been made to estimate acreage of Wheat crop using LISS-III data.

The technique uses hierarchical decision rules to classify the crop of interest. Initial zero fills, cloud, non agriculture (water, sand, urban areas, etc.) and forest features were marked out. Then the crop of interest was discriminated from competing crops prevalent in that area.Remote sensing technology has potential in estimating crop acreage at district, regional and national level. Many crop acreage estimation studies have been carried out using remotely sensed data. As mentioned above Uttarakhand is a hilly state so to estimating 
accurate crop acreage some techniques must be developed. The study shows that use of different techniques to estimate pre-harvest wheat acreage in hilly areas using IRS LISS III data.

\section{Objectives And Study Area}

The main objectives of the study are to:

- $\quad \square$ Estimate preharvest wheat acreage.

- $\square$ Develop different techniques for the acreage estimation of wheat crop in Uttarakhand state.

Uttarakhand located $3015 \mathrm{~N}$ latitude and $7915 \mathrm{E}$ longitude is a hilly state. All 13 districts of Uttarakhand state were selected for wheat acreage estimation. It is sown from last week of October to second week of December. The crop reaches flowering stage around mid-February and harvesting commences from April to first week of May.

Table-1: Specifications of Resourcesat sensor

\begin{tabular}{|l|l|}
\hline Specification & LISS-III \\
\hline Instantaneous geometric field of view $(\mathrm{m})$ & 23.5 \\
\hline Spectral bands (micrometer) & B2:0.52-0.59 \\
& B3:0.62-0.68 \\
& B4:0.77-0.86 \\
& B5:1.55-1.70 \\
\hline Swath $(\mathrm{km})$ & 141 \\
\hline Integration time (msec) & 3.32 \\
\hline Quantization (bits) & 7 \\
& MIR band has 10 bits quantization. \\
& Selected 7 bits out of 10 bit transmitted by data \\
\hline No. Of gains & handling system. \\
\hline & 4 for B2,B3 and B4 for B5 dynamic range obtained by \\
\end{tabular}

\section{Satellite data:}

\section{Data Used}

Table 2: IRS-P6-Resourcesat-2: LISS-III data has been used, the path and row is given below:

\begin{tabular}{|l|l|l|}
\hline SENSOR & PATH/ROW & STATE \\
\hline LISS-III & $96 / 49$ & Uttarakhand \\
\hline LISS-III & $96 / 50$ & Uttarakhand \\
\hline LISS-III & $97 / 49$ & Uttarakhand \\
\hline LISS-III & $97 / 50$ & Uttarakhand \\
\hline LISS-III & $98 / 49$ & Uttarakhand \\
\hline LISS-III & $98 / 50$ & Uttarakhand \\
\hline LISS-III & $98 / 51$ & Uttarakhand \\
\hline LISS-III & $99 / 49$ & Uttarakhand \\
\hline
\end{tabular}

\section{Collateral data:}

\section{Wheat Acreage statistics from Agriculture department}

Historical district level wheat statistics from 2005 to 2008 for districts for all 13 districts were compiled and used to analyze the accuracy of Pre-harvest wheat acreage estimation.

Shape file of the boundary of districts of Uttarakhand state from SOI has been used. Topo-sheets and images of the study area were also used for GT (Ground Truth).

\section{Ground truth}

Ground truth for wheat crop was carried out during March month in Uttarakhand state. Global Positioning System was used to locate GT points where latitude and longitude of particular field was noted. Other information gathered was extent of crop of interest, percent ground cover, crop stage, etc. Other information which has been collected is given in the table-4:

Table-3: G.T. (Ground truth) sheet which has been used is given below:

\begin{tabular}{|l|l|l|l|l|l|l|}
\hline S.no. & $\begin{array}{l}\text { District } \\
\text { name }\end{array}$ & $\begin{array}{l}\text { Year of } \\
\text { observation }\end{array}$ & $\begin{array}{l}\text { Crop under study } \\
\text { and } \\
\text { competing crops }\end{array}$ & $\begin{array}{l}\text { State, District, } \\
\text { Village name }\end{array}$ & $\begin{array}{l}\text { Date } \\
\text { observation }\end{array}$ & Geog. Latitude \\
\hline $\begin{array}{l}\text { Geog. } \\
\text { Longitude }\end{array}$ & $\begin{array}{l}\text { Size of } \\
\text { crop ield }\end{array}$ & Crop health & $\begin{array}{l}\text { Crop cover on } \\
\text { ground }\end{array}$ & $\begin{array}{l}\text { Free hand field } \\
\text { sketch }\end{array}$ & $\begin{array}{l}\text { Field photograph } \\
\text { (Overview) }\end{array}$ & $\begin{array}{l}\text { Field photograph } \\
\text { (Close view) }\end{array}$ \\
\hline
\end{tabular}

In the continuation of the work to estimate pre-harvest wheat acreage/Production of Uttarakhand state, the methodology which has been adopted is given below: 


\section{Methodology}

The major steps involved in the methodology that has been formulated for remote sensing based crop acreage estimation are as follows:

- Acquisition of satellite data

- Data processing

- Geo-referencing of Data IRS P6 LISS-III

- Mosaicing of different geo-referenced scenes: Total 8 scenes of Uttarakhand have been joined together

- Data subset (District wise)

- Collection of Ground truth information

Table 4: Ground based information will be collected in the given format:

\begin{tabular}{|c|c|c|c|c|c|c|}
\hline S. No. & $\begin{array}{l}\text { District } \\
\text { name }\end{array}$ & $\begin{array}{c}\text { Year of } \\
\text { observation }\end{array}$ & $\begin{array}{c}\text { Crop under study } \\
\text { and other competing } \\
\text { crops }\end{array}$ & $\begin{array}{l}\text { State/District/ } \\
\text { Village name }\end{array}$ & $\begin{array}{c}\text { Date of } \\
\text { observation }\end{array}$ & Geog. Latitude \\
\hline $\begin{array}{c}\text { Geog. } \\
\text { Longitude }\end{array}$ & $\begin{array}{l}\text { Size of crop } \\
\text { field }\end{array}$ & Crop health & $\begin{array}{l}\text { Crop cover on } \\
\text { ground }\end{array}$ & $\begin{array}{c}\text { Free hand field } \\
\text { sketch }\end{array}$ & $\begin{array}{l}\text { Field photograph } \\
\text { (Overview) }\end{array}$ & $\begin{array}{c}\text { Field } \\
\text { photograph } \\
\text { (Close view) }\end{array}$ \\
\hline
\end{tabular}

- Analysis of satellite data

- Modified NDVI image generation from geo-referenced satellite data: The images were converted to normalised difference vegetation index (NDVI) where NDVI is calculated as:

NDVI=NIR-R/NIR+R

Where NDVI range scaled between 0 to 200 .

- Masking out agriculture area from other classes using spatial modelling.

- Image forward only Agriculture area from recoded image using spatial modelling.

- Supervised classification of above forwarded image with the help of above mentioned ground truth sheet.

\section{Classification of images using hierarchical decision rules}

Maximum likelihood classification requires generation of training sites for each class. This is very difficult so here classification based on hierarchical decision rule based classification is an estimation procedure where step-by-step other features are initially masked out to obtain feature of interest. First data loss due to zero fills and cloud cover and non-agriculture classes like water bodies, urban areas, wasteland, cloud shadows etc. are eliminated. It has followed by masking out of vegetated areas like forest and plantation etc. Finally the crop of interest is classified by masking out competing crops present in that area in that time period.

- Acreage estimation of crops for plain region

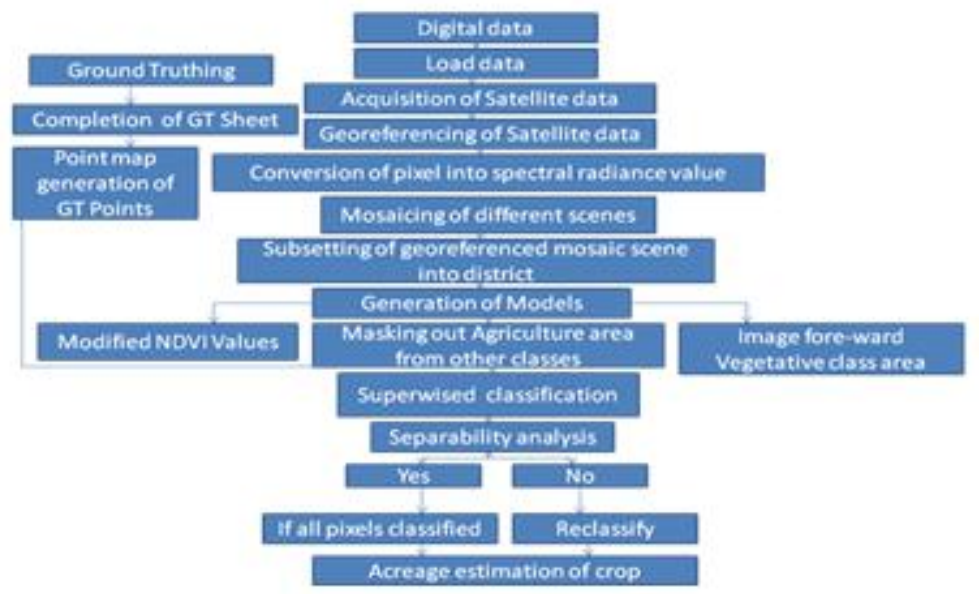

Figure1-Flow chart of Methodology for Acreage estimation

* This methodology is appropriate for plain area but in hilly area some of the wheat pixels were going into shadow portion so it is difficult to classify those pixels so a new method has been adopted -Breakpoint editor in ERDAS IMAGINE 9.3 is used to highlight those pixels which are going to shadow portion in satellite image so digitized this area and add to the wheat classified area. 


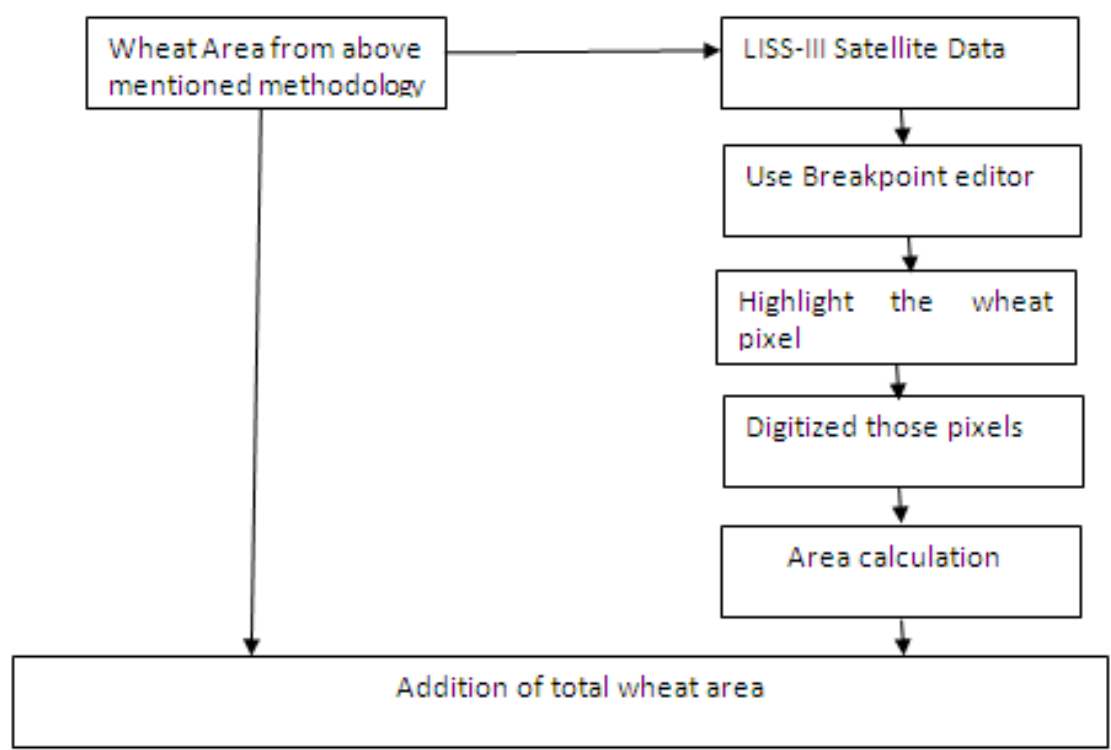

Figure-2: Additional Methodology for Acreage estimation of Wheat crop in Hilly area of Uttarakhand state

\section{Yield estimation}

Relationship between MNDI values and yield have been find out for all 13 districts of Uttarakhand state, during last 6 years, around 600 ground truth points have been collected, in those points approximately yield was also collected, based on these values model has been developed to find relationship between MNDVI values and yield, different models have been prepared for 13 districts' of Uttarakhand state. Yield has been estimated on the basis of model.

\section{Production estimation}

Production has been estimated on the basis of the following formula which gives relationship between production, acreage and productivity:

Production of crop $=$ Estimated yield $*$ Acreage of crop

\section{Geo-referencing of satellite data}

\section{Results And Discussion}

Image-to-image registration was done with an accuracy level of less than half a pixel.

\section{Ground-truth Details}

The competing crops were sugarcane, mustard etc. In Uttarakhand the ground truth period was January. Wheat was in flowering stage.The canopy cover of the plant is very poor and soil exposure is very high. On the other hand we see the flowering stage of wheat crop. This indicates variability in the condition of wheat crop within the state. Variability in the wheat crop condition is mainly observed due to irrigated and un-irrigated regions with in the state. Spectral profile is based on single pixel only. Spectral plot of wheat and mustard crop in Uttarakhand state shows good separability between both crops in plain region.

Table-5: District-wise Pre-harvest Acreage/Production estimation of Wheat crop for Uttarakhand state is given below for the year 2013-14:

\begin{tabular}{|l|r|r|r|}
\hline District & Area(ha) & Production(m-t) & Productivity(qtl/ha) \\
\hline Chamoli & 13801.772 & 18608.21 & 13.4824766 \\
\hline Dehradun & 23959.69 & 48097.61 & 20.07438661 \\
\hline Haridwar & 41748.78 & 109258.6 & 26.17049887 \\
\hline Pauri Garhwal & 37634.939 & 36248.83 & 9.631695803 \\
\hline Rudraprayag & 11366.09 & 12330.5 & 10.84849671 \\
\hline Tehri Garhwal & 32645.453 & 39344.35 & 12.05201462 \\
\hline Uttarkashi & 11687.378 & 18265.35 & 15.6282718 \\
\hline Almora & 44387.15 & 50106.88 & 11.28859929 \\
\hline Bageshwar & 15402.9264 & 16979.46 & 11.02352878 \\
\hline Champawat & 12272.73 & 13812.53 & 11.25465076 \\
\hline Nainital & 26706.04 & 56225.43 & 21.05345158 \\
\hline Pithoragarh & 26648.77 & 36254.44 & 13.60454535 \\
\hline Udhamsinghnagar & 99592.13 & 377005.1 & 37.8549048 \\
\hline
\end{tabular}


The total acreage estimation of wheat crop in Uttarakhand state is 397853.8484 ha and production is about $832537.3 \mathrm{~m}-\mathrm{t}$ in whole Uttarakhand state.
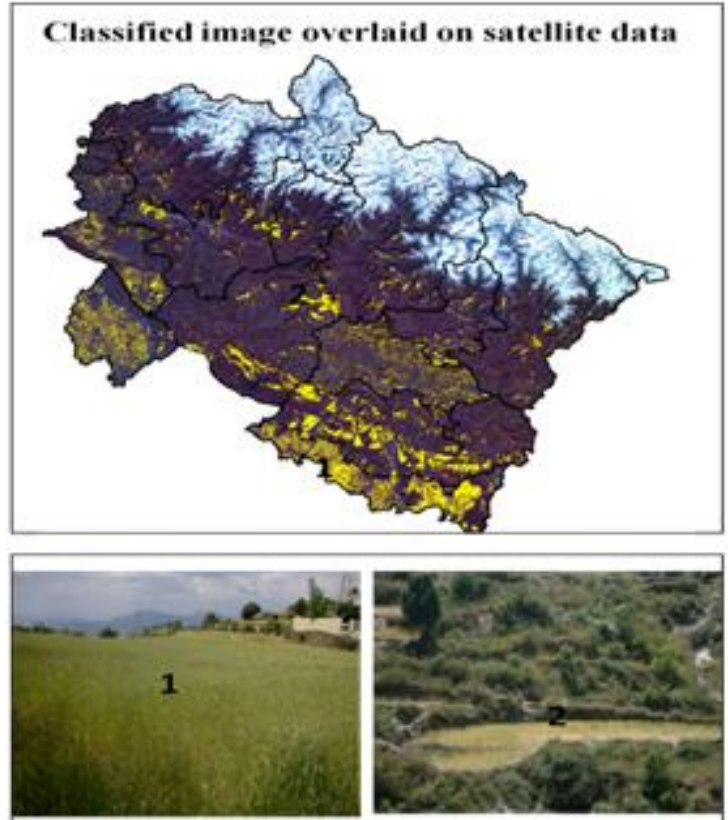

Figure 3: Classified image overlaid on Satellite data of Uttarakhand state

\section{Conclusion}

There is a significant positive relationship between remotely sensed NDVI and field level yield. This clearly shows the potential of using NDVI for wheat crop yield prediction. To forecast production before harvest facilitate the formulation of workable marketing strategies leading to better export/import of crop in the state, which will help to lead better economic condition of the state. Yield estimation would help agriculture department in assessment of productivity of land for specific crop. Pre-harvest wheat acreage/production estimation, is useful to facilitate the reliable and timely estimates and enable the administrators and planners to take strategic decisions on import-export policy matters and trade negotiations.

\section{References}

[1]. Ajai 1992. Cotton Acreage Estimation and Condition Assessment. In Natural Resources Management- a new perspective, NNRMS Bangalore p267.

[2]. Bhgia, N.,Oza M.P.,Patel J.H., Dadhwal V.K., 1996. An approach for all India wheat production forecasting using remote sensing data. Scientific note: RSAM/SAC/CAPE-II/SN/53/96 April 1996,19p.

[3]. Bhagia,N., Oza, M.P., Rajak, D.R., Singh, R.P., Sehgal, V.K., Ravi, N.,Srivastava, H.S.Patel, J.H., Ray, S.S. and Dabhwal, V.K., 1997. An attempt to make national wheat production forecast using multidate WiFS data for 1996-97 season. Bull.National Natural Resources Management System, NNRMS(B)-21,54-58.

[4]. Bhagia, N.,Rajak, D.R.,Oza, M.P.,Jaishankar R. and Dadhwal V.K.;2002.All India wheat production forecasting using multi-date WiFS and meteorological data for 2001-2002 season. Scientific Note: RSAM/SAC/FASAL-TD/SN/14/MAY2002.

[5]. Cotton area estimation using multi-temporal AWiFS data-A Feasibility study Nita Bhagia, M.R.Bhuyan, M.P.Oza, N.K.Patel, J.S.Parihar, Khalid Mehmood, Vijay Singh, Mahest Chodvadiya and Navneet patel, G.D.Bairagi, Sanjay Apturkar, D.C.Loshali

[6]. Dadhwal,V.K.., \& Ray, S.S.(2000), Crop assessment, Indian journal of Agriculture Economics, 2 (1947)-4, 55-67

[7]. Groten, S.M.E. (1993). NDVI- Crop monitoring and early yield assessment of Burkina Faso. International journal of Remote sensing 14 (8), 1495-1515.

[8]. Haig L.A.S.Sawasawa, 2003: Crop yield estimation: Integrating RS, GIS and Management factors.

[9]. M.H.Kalubarme, Alka Sharma and R.K.Sood .Wheat production forecast in hilly Terrains of Himanchal Pradesh. ISG Newsletter.

[10]. M.M.Kimothi, M.H.Kaluborme, Sujaya Dutta, Rajendra Thapa, and R.K Sood,.(1997).Remote sensing of horticultural plantations in Kumarsain Tehsil (Shimla district).ISRS Journal, Vol.25,No.1.

[11]. Oza, M.P.,Bhagia, N.L., Rajak,D.R. and Dadhwal, V.K.2002. All India wheat inventory using multi date IRS WiFS and weather data, the international Archives of the Photogrammetry, Remote Sensing and Spatial information Sciences, Vol.34, Part XXX.

[12]. Oza M.P., Bhagia, N.L.Rajak, D.R. and Dadhwal, V.K.,2002.All India wheat inventory using multi-date IRS WiFS and weather data, The international Archives of the photogrammetry, Remote sensing and spatial Information Sciences, Vol.34,Part XXX.

[13]. S.C.Bhatt (Editor) (1997). Nothern Zone Gyan PublishingThe Encyclopaedic district Gazetteers of India. Northern Zone Gyan Publishing House. New Delhi- 110002.

[14]. Wang,R.Y.(1986) An approach to tree- classifier design based on hierarchical clustering. International Journal of Remote Sensing; Vol.7:75-88 